\title{
CARACTERIZAÇÃO MORFOMÉTRICA DE UMA SUPERFÍCIE CÁRSTICA DO VALE DO RIBEIRA, SÃO PAULO (NÚCLEO CABOCLOS - PETAR)
}

\author{
José Antonio FERRARI \\ Silvio Takashi HIRUMA \\ Ivo KARMANN
}

\begin{abstract}
RESUMO
Este trabalho apresenta um método para a obtenção de parâmetros morfométricos de paisagens cársticas a partir de técnicas de geoprocessamento. Foram obtidos valores de rugosidade, declividade, amplitude do relevo, densidade da drenagem e circularidade em depressões poligonais fechadas. O método é aplicado para obter uma assinatura quantitativa da totalidade da paisagem cárstica, bem como para a caracterização individual das depressões fechadas. Foram realizadas análises espaciais e correlações dos diversos parâmetros morfométricos obtidos. Os dados mostram que depressões mais circulares possuem menor área e baixo desenvolvimento de drenagem. As depressões de maior área são menos circulares e possuem rede de drenagem e amplitude de relevo maiores. Os dados obtidos, integrados com conhecimentos prévios da área, permitem interpretar que a forma planimétrica das depressões na região depende da anisotropia da resistência ao desenvolvimento da drenagem.
\end{abstract}

\section{ABSTRACT}

A method to obtain morphometric parameters of karst surfaces is proposed based on GIS techniques. An example of application is presented resulting in a quantitative signature of the total carbonatic surface area as well as in an individual characterization analysis of closed depressions. The following parameters were calculated: roughness, slope, topographic amplitudes, drainage density and circularity of closed depressions. Spatial and correlation analysis of the main parameters were done. The results show that more circular depressions are characterized by smaller areas and little drainage development. Larger depressions present lower circularity and possess well developed drainage networks and a higher topographic range. Based on the spatial distribution of the parameters and on the circularity values, the planimetric form of the depressions is interpreted as a result of anisotropy of the resistance of bedrock to drainage development.

\section{INTRODUÇÃO}

A análise morfométrica permite diminuir o grau de subjetividade na avaliação do relevo, favorecendo a comparação de paisagens envolvidas em contextos climáticos ou geológicos diferenciados. A correlação entre parâmetros morfométricos e a ocorrência de determinados tipos de processos naturais pode levar ao estabelecimento de modelos de evolução da paisagem e, conseqüentemente, à definição de formas racionais de uso e ocupação do solo.

Técnicas quantitativas vêm sendo comumente utilizadas para o estudo de terrenos cársti$\cos$, dentre as quais podem ser citadas aquelas para caracterizar depressões poligonais fechadas, verificar seu padrão de dispersão espacial e sua relação com a rede de drenagem (WILLIAMS, 1972; McCONNEL \& HORN, 1972; PRINGLE, 1973; MILLER, 1982) e aquelas utilizadas para obter o índice de irregularidades ou a variabilidade não sistemática da superfície do terreno (DAY, 1979).

Este trabalho apresenta um novo método para a caracterização morfométrica da totalidade da superfície cárstica e também para a caracterização individual de depressões fechadas. O trabalho utiliza ferramentas computacionais de uso comum em geociências, característica importante para a difusão da técnica. 
O trabalho foi desenvolvido em um setor do carste tropical úmido do Alto Vale do Ribeira, localizado no Núcleo Caboclos, dentro do Parque Estadual Turístico do Alto Ribeira (PETAR), que engloba setores dos municípios de Apiaí e Iporanga (SP) (FIGURA 1).

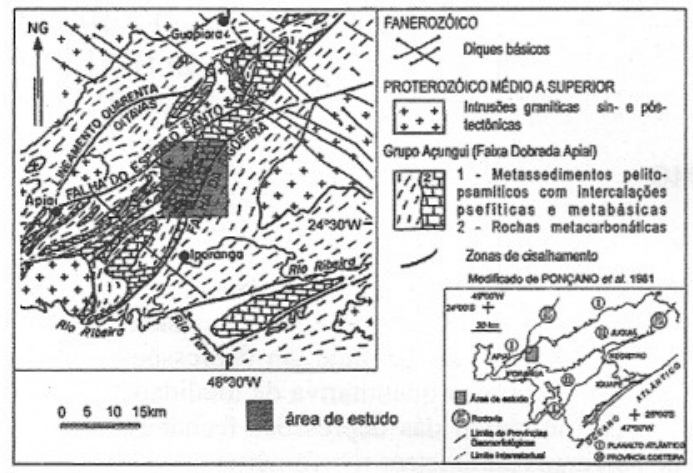

FIGURA 1 - Contexto geológico regional da área de estudo (adaptado de KARMANN, 1994).

\section{O CARSTE DO NÚCLEO CABOCLOS}

O Núcleo Caboclos está inserido numa região climática de transição entre o clima quente das latitudes baixas e o clima temperado mesotérmico das latitudes médias, típico da região sul. NIMER (1977) classifica o clima da área como subseqüente e superúmido, sem estação seca. A média anual de precipitação para o período de 1970-1996 é de 1.963,3 mm, sendo que a estação chuvosa (outubro a março) concentra $1.281,5 \mathrm{~mm}$ e a estação mais seca (abril a setembro), $681,8 \mathrm{~mm}$. As médias térmicas anuais normalmente encontram-se entre $20^{\circ} \mathrm{e}$ $22^{\circ} \mathrm{C}$. As amplitudes térmicas anuais são relativamente baixas, em grande parte devido à presença da vizinhança oceânica (TAVARES \& GUTJHAR, 1999). Na região, este clima permite o desenvolvimento da Floresta Perenifólia Higrófila Costeira (ALONSO, 1977), que apresenta uma fisionomia alta e densa, conseqüência da variedade de espécies pertencentes a várias formas biológicas e estratos. Seus elementos mais altos podem alcançar de 25 a 30 metros. $\mathrm{O}$ grande número de lianas, epífitas, fetos arborescentes e palmeiras dá a esta floresta um caráter tipicamente tropical.

De acordo com a compartimentação tectônica definida por CAMPANHA (1991), os terrenos carbonáticos estão inseridos no Bloco
Lajeado, delimitado a sul pelo Lineamento da Figueira, e a norte, pelos lineamentos de Quarenta-Oitava e Carumbé. A FIGURA 1 ilustra o contexto geológico regional da área de estudo. Afloram na área de estudo litologias do Grupo Açungui: mármores puros a impuros intercalados com filitos, metarenitos e metassiltitos.

No quadro geomorfológico regional, a área situa-se na transição entre a Província do Planalto Atlântico e a Província Costeira (PONÇANO et al., 1981) (FIGURA 1). No entorno da área estudada, o Planalto Atlântico atinge cotas entre 900 e 950 metros; na Província Costeira a presença de serras alterna terrenos com cotas médias de 300 metros com cristas de mais de 800 metros de altitude.

$\mathrm{O}$ carste apresenta disposição geral NE-SW e ocupa um nível topográfico rebaixado aproximadamente 200 metros em relação ao Planalto de Guapiara (Planalto Atlântico), delimitando-se a leste pela escarpa que acompanha o Lineamento da Figueira (FIGURA 2). A altitude fica em torno dos 600 metros, podendo decair para até 150 metros no fundo do canyon do rio Pescaria. Os picos e cristas nos terrenos cársticos encontram-se rebaixados em relação aos picos e cristas das rochas não carbonáticas.

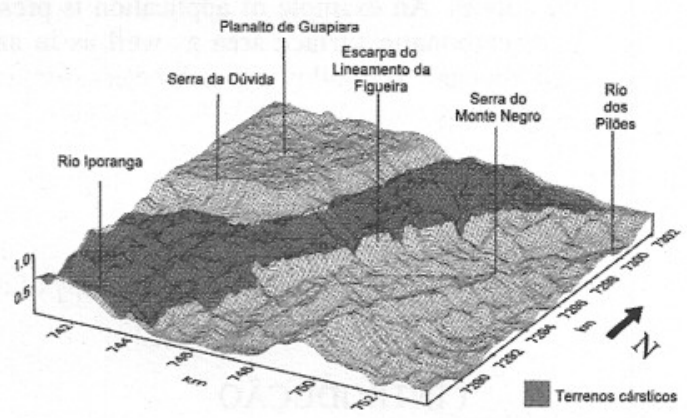

FIGURA 2 - Modelo digital de terreno. Os terrenos cársticos ocupam um nível topográfico rebaixado aproximadamente $200 \mathrm{~m}$ em relação ao Planalto de Guapiara, delimitando-se a leste pela escarpa que acompanha o Lineamento da Figueira.

O carste estudado está inserido na porção nordeste da Província Espeleológica do Alto Ribeira (KARMANN \& SÁNCHEZ, 1979). Nesta faixa de rochas carbonáticas o sistema cárstico é do tipo misto, com uma importante recarga alogênica em relação à autogênica. A injeção alogênica é absorvida quase que totalmente por sumidouros associados à zona de contato, onde incidem poljes (poliés) de contato e 
escarpamentos rochosos com pórticos de cavernas, enquanto a recarga autogênica é absorvida por fundos de bacias de drenagem centrípeta. A superfície cárstica abriga um variado conjunto de formas de relevo, cujo agrupamento permitiu um zoneamento morfológico, caracterizando, entre estes, domínios de carste poligonal, zonas fluviocársticas, fluviais e de transição entre estes (KARMANN, 1994). As rotas de fluxo da água subterrânea são de alto gradiente hidráulico e freqüentemente associadas a sistemas de cavernas com entalhamentos fluviais subterrâneos (canyons) que atingem até $60 \mathrm{~m}$. O sistema de cavernas mais extenso na área de estudo é o da Pescaria, com cerca de $3 \mathrm{~km}$ de condutos medidos em planta e 300m de desnível.

\section{PARÂMETROS ANALISADOS}

Segundo DAY (1979), o carste tropical é caracterizado por uma grande variaedade de formas de relevo, de difícil classificação, em parte porque nunca foram investigadas quantitativamente. Vários trabalhos de caracterização de superfícies cársticas centram foco principalmente em depressões fechadas e morros residuais, Tais técnicas morfométricas caracterizam apenas certos componentes do terreno. A extrema variabilidade do carste tropical requer uma abordagem mais geral, baseada na totalidade da superfície. Com estes argumentos, DAY (1979) propõe a utilização do índice de rugosidade como um discriminador de estilos de carstes tropicais.

Para HOBSON (1972), uma definição concisa de rugosidade de uma superficie é provavelmente impossível. Algumas definições são incompletas pois descrevem apenas poucas das propriedades físicas e matemáticas das superficies. Segundo esse autor, para a descrição de terrenos naturais, o parâmetro rugosidade deve ser estabelecido de modo a ser utilizado para descrever as irregularidades da superfície em diferentes escalas. Por sua vez, DAY (1979) utilizou a dispersão dos vetores perpendiculares a planos de superfície como indicador de rugosidade. No presente trabalho, o atributo rugosidade é obtido a partir da razão entre a área da superfície e a área planar, conforme sugerido por HOBSON (1972). Seguindo este método, superfícies planas apresentam índice 1, enquanto que, em superficies irregulares, o índice tende ao infinito. Este parâmetro determina a similaridade entre a área da superfície e a área planar da região analisada. Como existem interações entre o número e a magnitude das irregularidades do terreno, um mesmo índice de rugosidade pode expressar superfícies com características diferentes. Numa primeira análise, ao se comparar os índices de duas superfícies pelo método exposto, pode-se utilizar as amplitudes das superfícies para avaliar se o índice é condicionado pelo número de irregularidades ou por sua magnitude. Segundo HOBSON (1972), o índice de rugosidade obtido a partir da relação entre áreas é mais efetivo quando acompanhado por outros parâmetros, como por exemplo a dispersão dos vetores. Trabalhos mais recentes mostram que a dimensão fractal pode ser utilizada para indicar o quanto uma superfície é irregular (ELLIOT, 1989).

$\mathrm{O}$ índice de rugosidade foi obtido para o conjunto do carste, bem como para cada depressão poligonal fechada. Foram consideradas depressões fechadas todas as bacias cuja drenagem superficial converge para um ponto de absorção que injeta a água para rotas de fluxo subterrâneo. Uma vez que o objetivo do trabalho foi obter parâmetros quantitativos de depressões fechadas formadas sobre rochas carbonáticas, foram eliminadas as depressões cuja superfície estendia-se para outras litologias, como ocorre nas zonas de contato litológico. A população analisada totalizou 98 depressões.

$\mathrm{O}$ índice de circularidade foi utilizado como índice de forma para a caracterização das depressões. Segundo CHRISTOFOLETTI (1980), este índice, desenvolvido por MILLER (1953), expressa a relação existente entre a área da bacia hidrográfica e a área do círculo de mesmo perímetro (equação 1). Assim, quanto mais próximo de 1 o índice estiver, mais circular é a depressão.

Não existe uma escala qualitativa para os valores de circularidade: assim, neste trabalho, estabeleceu-se, de modo arbitrário, o valor 0,5 para separar as depressões poligonais fechadas em dois grupos.

$$
I c=\frac{\mathrm{A}}{\mathrm{Ac}} \quad \text { equação (1) }
$$

Onde: $I c=$ índice de circularidade; $A=$ área de bacia; $A c$ = área do círculo de perímetro igual ao da bacia considerada. 
Além dos parâmetros básicos para o cálculo da rugosidade e da circularidade, foram obtidos os seguintes atributos das depressões: altitude média, declividade média e máxima, amplitude do relevo (diferença entre o maior e o menor valor altimétrico da área analisada), comprimento total da drenagem e densidade de drenagem (HORTON, 1945).

\subsection{Rotina para obtenção dos dados}

Preliminarmente procedeu-se à digitalização da carta topográfica Mina do Espírito Santo 4-4 (JICA/DNPM, 1983), na escala 1:25.000. A partir de fotointerpretação na escala 1:25.000 foram traçados divisores de depressões fechadas (FIGURA 3) e restituída a rede de drenagem. Durante a fotointerpretação, verificaram-se imprecisões na carta topográfica em relação ao número de sumidouros mapeados e ao traçado da rede de drenagem. Os limites das áreas de rochas carbonáticas e não carbonáticas foram obtidos a partir do mapeamento geológico executado pela JICA/DNPM (1983), na escala $1: 25.000$.

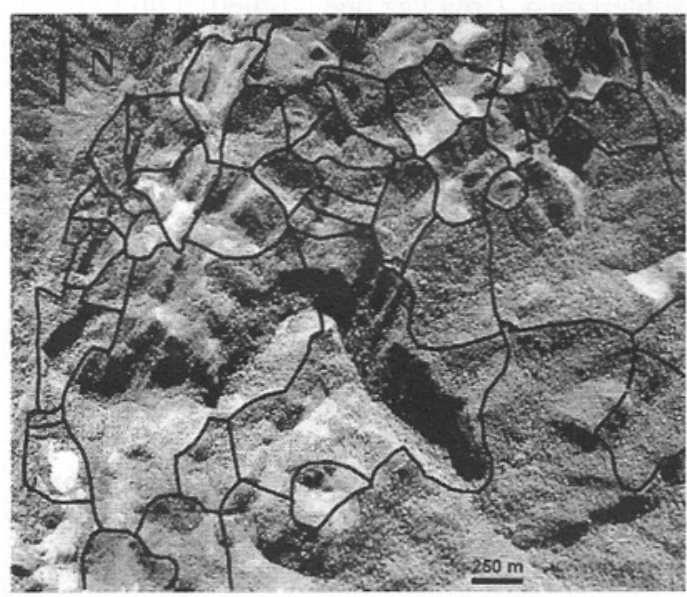

FIGURA 3 - Traçado de divisores de depressões fechadas a partir da interpretação de fotos aéreas na escala 1:25.000.

Todos os dados obtidos na etapa anterior foram digitalizados a partir do programa AUTOCAD. A FIGURA 4 apresenta a distribuição das depressões fechadas e da rede de drenagem na área de estudo. Com o auxílio do programa SURFER, foi elaborado um modelo digital do terreno (MDT) com resolução de 25 metros, a partir das curvas de nível previamente digitalizadas. Posteriormente, o MDT foi exportado para o programa IDRISI.

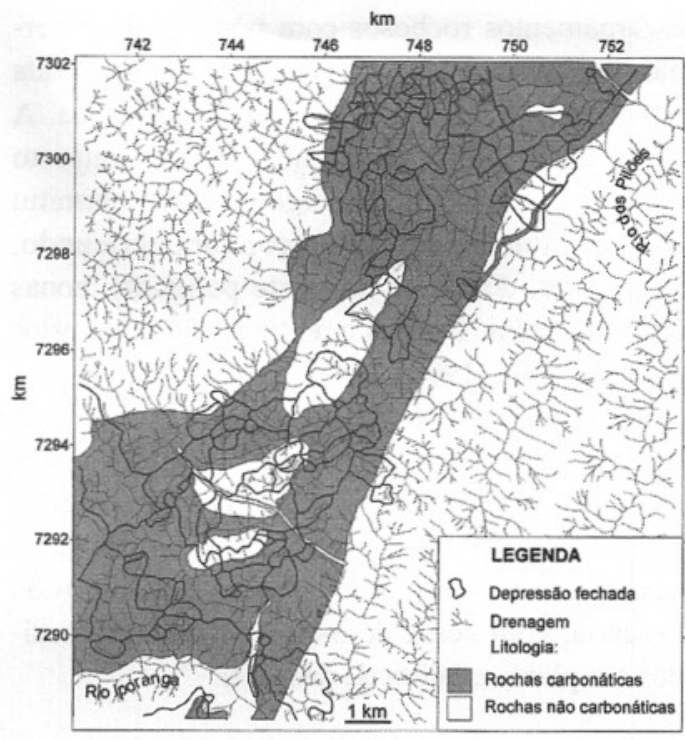

FIGURA 4 - Terrenos cársticos e depressões fechadas na área de estudo. Base cartográfica e geológica: Projeto Anta Gorda (JICA/DNPM, 1983). Coordenadas: Projeção Universal Transversa de Mercator.

Os mapas vetoriais das depressões fechadas e da rede de drenagem foram utilizados na elaboração de imagens raster no programa IDRISI. A imagem das depressões foi utilizada como guia para a extração de informações do modelo digital do terreno, da carta de declividade (elaborado a partir do MDT) e do mapa da rede de drenagem. Os seguintes parâmetros foram extraídos das depressões fechadas com a utilização do programa IDRISI: declividade média e máxima, perímetro, amplitude do relevo, altitude média e comprimento da drenagem. Num processamento posterior dos parâmetros extraídos, foram calculados a densidade de drenagem e o índice de circularidade.

A rugosidade do relevo foi calculada a partir dos valores de área planar e de superfície obtidos no programa SURFER.

Todos os parâmetros relativos às depressões foram inseridos no gerenciador de bases de dados do programa IDRISI. A partir do estabelecimento desta base foi possível realizar análises espaciais para verificar tendências na distribuição das depressões.

\section{RESULTADOS OBTIDOS}

$\mathrm{O}$ índice de rugosidade obtido para a totalidade do carste é 1,0993, com uma amplitude de 
relevo de 630 metros. A TABELA 1 apresenta os dados utilizados para o cálculo. A TABELA 2 apresenta os parâmetros morfométricos obtidos das 98 depressões poligonais fechadas da região do Núcleo Caboclos. Como se pode observar, o valor médio da rugosidade das depressões fechadas é semelhante ao da rugosidade obtida para a totalidade do carste.

\begin{tabular}{|c|c|c|c|}
\hline $\begin{array}{c}\text { Área da } \\
\text { superfície } \\
\left(\mathrm{km}^{2}\right)\end{array}$ & $\begin{array}{c}\text { Área planar } \\
\left(\mathrm{km}^{2}\right)\end{array}$ & $\begin{array}{c}\text { Menor altitude } \\
(\text { metros })\end{array}$ & $\begin{array}{c}\text { Maior altitude } \\
\text { (metros) }\end{array}$ \\
\hline 53,47 & 48,64 & 215 & 845 \\
\hline \multicolumn{2}{|c|}{ Rugosidade: 1,0993} & \multicolumn{2}{|c|}{ Amplitude: 630} \\
\hline
\end{tabular}

TABELA 1 - Valores de área e amplitude de relevo para a totalidade do carste.

\begin{tabular}{|c|c|c|c|c|c|c|c|c|c|c|c|}
\hline & \multicolumn{11}{|c|}{ PARÂMETROS MORFOMÉTRICOS } \\
\hline & $\begin{array}{l}\text { Declive } \\
\text { médio } \\
\text { (graus) }\end{array}$ & $\begin{array}{l}\text { Declive } \\
\text { máximo } \\
\text { (graus) }\end{array}$ & $\begin{array}{c}\text { Perímetro } \\
(\mathrm{km})\end{array}$ & $\begin{array}{l}\text { Amplitude } \\
\text { (metros) }\end{array}$ & $\begin{array}{c}\text { Altitude } \\
\text { média } \\
\text { (metros) } \\
\end{array}$ & \begin{tabular}{|c|}
$\begin{array}{c}\text { Comprimento } \\
\text { da drenagem } \\
(\mathrm{km})\end{array}$ \\
\end{tabular} & $\begin{array}{c}\text { Densidade } \\
\text { da drenagem } \\
\left(\mathrm{km} / \mathrm{km}^{2}\right) \\
\end{array}$ & Ic & $\begin{array}{l}\text { Área } \\
\text { planar } \\
\left(\mathrm{km}^{2}\right) \\
\end{array}$ & $\begin{array}{c}\text { Area da } \\
\text { superficie } \\
\left(\mathrm{km}^{2}\right)\end{array}$ & Rugosidade \\
\hline máximo & 33,70 & 64,39 & 7,29 & 491,69 & 739,14 & 4,93 & 7,14 & 0,66 & 1,22 & 1,27 & 1,2657 \\
\hline minimo & 3,01 & 6,56 & 0,45 & 2,73 & 204,54 & 0,00 & 0,00 & 0,23 & 0,0025 & 0,003 & 1,0011 \\
\hline média & $\underline{18,73}$ & $\underline{39,42}$ & $\underline{2.06}$ & $\underline{138.15}$ & $\underline{591,26}$ & $\underline{0,59}$ & $\underline{2.52}$ & $\underline{0.44}$ & $\underline{0,16}$ & $\underline{0,18}$ & 1,0914 \\
\hline $\begin{array}{l}\text { desvio } \\
\text { padrắo }\end{array}$ & 6,34 & 9,58 & 1,29 & 89,24 & 91,48 & 0,91 & 2,04 & 0,08 & 0,22 & 0,25 & 0,0548 \\
\hline $\begin{array}{c}\text { coef. de } \\
\text { variaçăo } \\
\text { (\%) }\end{array}$ & 33,85 & 24,30 & 62,44 & 64,60 & 15,47 & 155,35 & 80,72 & 19,27 & 136,51 & 139,73 & 5,0245 \\
\hline
\end{tabular}

TABELA 2 - Parâmetros morfométricos das 98 depressões fechadas do Núcleo Caboclos.

Os dados também mostram que, apesar de apresentarem áreas muito variadas, as depressões fechadas têm pouca variabilidade em sua circularidade, $19,27 \%$. O valor médio da circularidade $(0,44)$ indica que a maioria das depressões fechadas não possui forma circular. A grande variabilidade dos parâmetros da drenagem resulta da ausência de canais mapeáveis na escala 1:25.000 em muitas depressões.

Para verificar a existência de correlação entre a forma da depressão fechada e outros parâmetros obtidos, a população das depressões foi dividida em dois grupos (acima e abaixo de 0,5) (FIGURA 5). Os resultados obtidos podem ser observados na TABELA 3. A aplicação do teste $t$ ao nível de significância de 0,05 , para os resultados obtidos nos dois grupos, permite aceitar a hipótese de que as depressões fechadas mais circulares $(I c>0,5)$ possuem valores médios de área planar, perímetro, comprimento total da drenagem, densidade de drenagem, amplitude do relevo e declividades máximas inferiores aos observados para as depressões fechadas menos circulares $(I c<0,5)$. No entanto, os valores de declividade média, área em superfície, rugosidade e altitude média não apre- sentam diferenças significativas ao nível de significância de 0,05 .

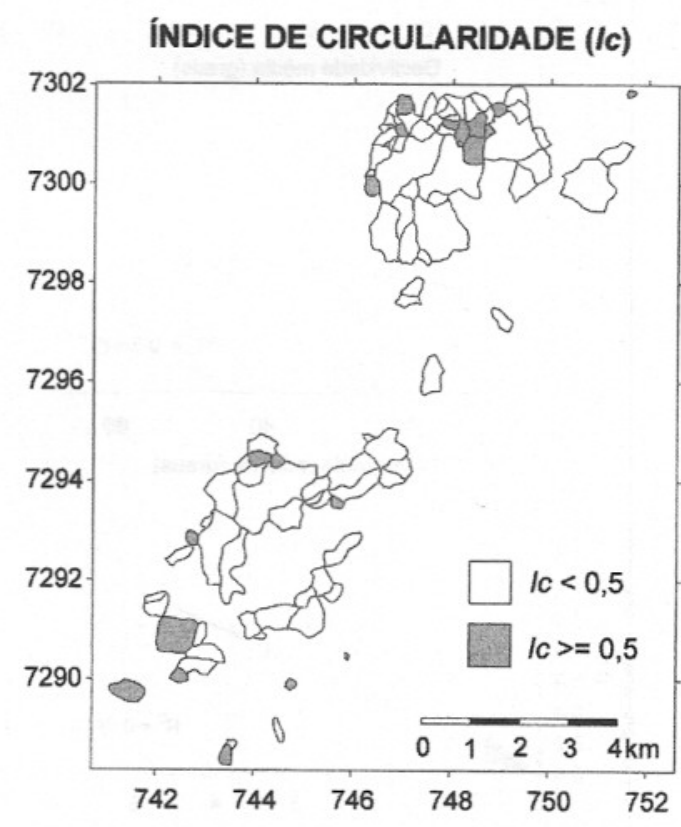

FIGURA 5 - Mapa das depressões fechadas mostrando a distribuição espacial do índice de circularidade $(l c)$. 


\begin{tabular}{|c|c|c|c|c|c|c|c|c|c|c|c|}
\hline & $\begin{array}{l}\text { Declive } \\
\text { médio } \\
\text { (graus) }\end{array}$ & $\begin{array}{l}\text { Declive } \\
\text { máximo } \\
\text { (graus) }\end{array}$ & $\begin{array}{c}\text { Perímetro } \\
(\mathrm{km})\end{array}$ & $\begin{array}{l}\text { Amplitude } \\
\text { (metros) }\end{array}$ & $\begin{array}{c}\text { Altitude } \\
\text { média } \\
\text { (metros) }\end{array}$ & $\begin{array}{c}\text { Comprimento } \\
\text { da drenagem } \\
(\mathrm{km})\end{array}$ & $\begin{array}{c}\text { Densidade } \\
\text { da drenagem } \\
\left(\mathrm{km} / \mathrm{km}^{2}\right)\end{array}$ & Ic & $\begin{array}{l}\text { Área } \\
\text { planar } \\
(\mathrm{km})\end{array}$ & $\begin{array}{c}\text { Área da } \\
\text { superficie } \\
(\mathrm{km})\end{array}$ & Rugosidade \\
\hline & \multicolumn{11}{|c|}{ Ic $<00,5 \quad n=74$} \\
\hline Máximo & 33,70 & 64,39 & 7,29 & 491,69 & 739 & 4,93 & 7,14 & 0,4909 & 1,2219 & 1,2677 & 1,2657 \\
\hline Minimo & 5,29 & 16,81 & 0,50 & 7,62 & 304 & 0,00 & 0,00 & 0,2350 & 0,0044 & 0,0048 & 1,0036 \\
\hline Média & 18.97 & $\underline{41.17}$ & 2.28 & 149,46 & 592 & $\underline{0.69}$ & $\underline{276}$ & 0.4052 & 0.1867 & 0.2076 & 1.0947 \\
\hline Desvio & 6,37 & 8,52 & 1,35 & 91,89 & 81 & 0,98 & 1,94 & 0,0604 & 0,2430 & 0,2765 & 0,0563 \\
\hline $\begin{array}{c}\text { Coef. de } \\
\text { variaçăo } \\
\text { (\%) }\end{array}$ & 33,56 & 20,69 & 59,31 & 61,48 & 14 & 142,62 & 70,25 & 14,8968 & 130,1240 & 133,2243 & 5,1452 \\
\hline \multicolumn{12}{|c|}{ lc $>0,5 \quad n=24$} \\
\hline Máximo & 31,67 & 49,36 & 3,14 & 282,49 & 720 & 2,23 & 5,98 & 0,6625 & 0,4659 & 0,5127 & 1,2102 \\
\hline Minimo & 3,01 & 6,56 & 0,45 & 2,73 & 205 & 0,00 & 0,00 & 0,5031 & 0,0025 & 0,0025 & 1,0011 \\
\hline Média & 17.94 & 33,72 & 1,34 & 101,25 & $\underline{590}$ & 0.25 & 1,76 & 0.5523 & 0.0838 & 0.0919 & 1.0803 \\
\hline Desvio & 6,33 & 10,77 & 0,66 & 69,67 & 121 & 0,49 & 2,21 & 0,0455 & 0,1004 & 0,1109 & 0,0492 \\
\hline $\begin{array}{c}\text { Coef. de } \\
\text { variaçä } \\
\text { (\%) }\end{array}$ & 35,27 & 31,95 & 49,15 & 68,81 & 21 & 198,01 & 125,40 & 8,2369 & 119,8476 & 120,7007 & 4,5535 \\
\hline
\end{tabular}

TABELA 3 - Parâmetros morfométricos para depressões fechadas com circularidade (Ic) acima e abaixo de 0,5.
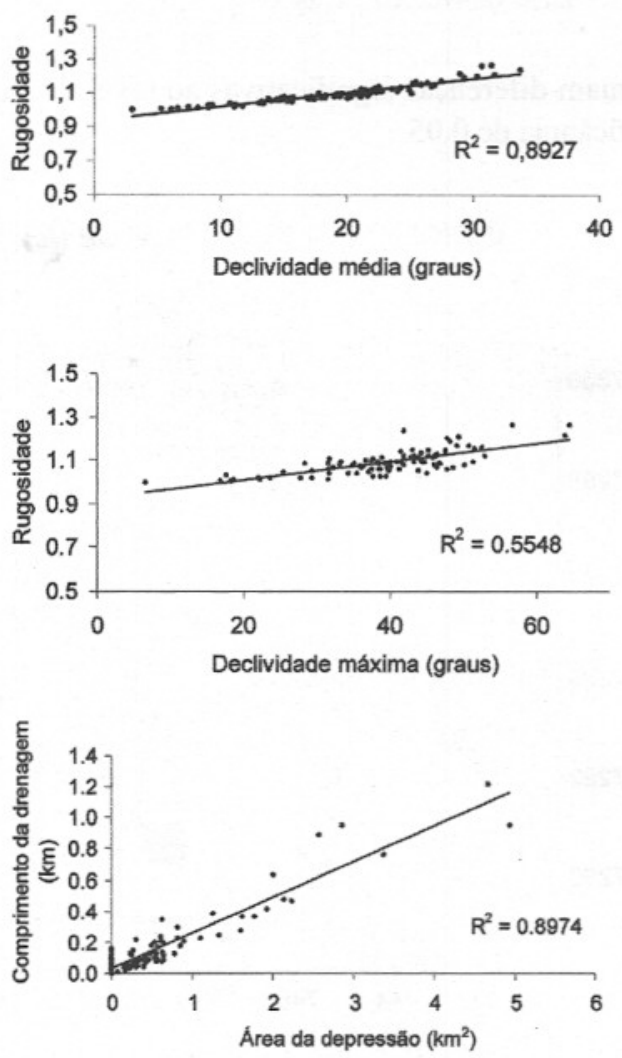

FIGURA 6 - Correlações mais significativas entre os parâmetros analisados.
Os parâmetros obtidos para as depressões fechadas foram correlacionados segundo o modelo linear. A correlação linear entre a rugosidade do relevo e a declividade média apresenta índice de determinação de $89 \%$; considerando-se a declividade máxima, o valor cai para $55 \%$. A correlação entre a área da depressão e o comprimento da drenagem apresenta um índice de determinação de $90 \%$ (FIGURA 6).

Outras correlações entre os parâmetros utilizando o modelo linear não apresentaram bons índices de determinação; no entanto, algumas tendências foram observadas: o aumento da densidade da drenagem é acompanhado por um aumento da área das depressões fechadas, a circularidade diminui com o aumento do comprimento total dos canais de drenagem e com o aumento da densidade de drenagem, a amplitude do relevo aumenta quando a densidade de drenagem, o comprimento total da drenagem e a rugosidade aumentam.

Os parâmetros obtidos também foram utilizados em análises espaciais para verificar se a distribuição das depressões fechadas era condicionada por algum fator. Foram elaborados 
mapas de anomalias positivas e negativas em torno da média para os diferentes parâmetros obtidos. A análise visual destes mapas permitiu avaliar padrões de dispersão e de concentração em função do fator analisado. $\mathrm{O}$ resultado que mais chamou a atenção foi o forte agrupamento de depressões fechadas com áreas abaixo da média da população total localizadas na porção norte da região (FIGURA 7).

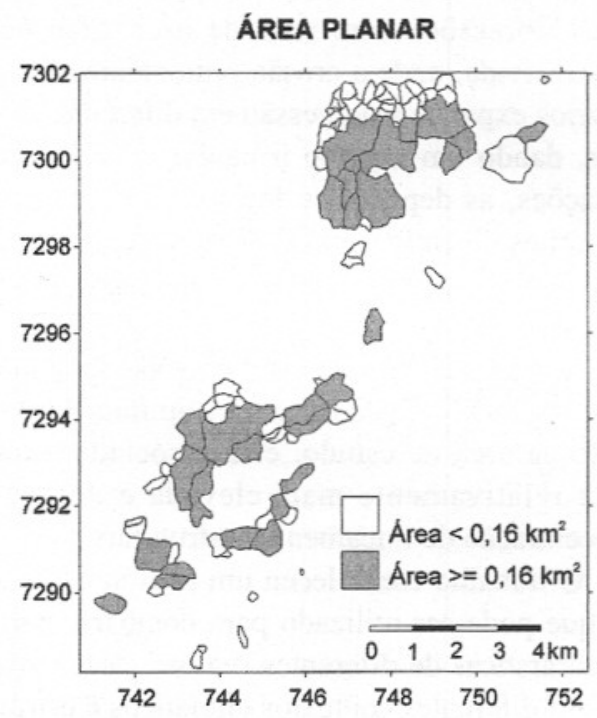

FIGURA 7 - Mapa das depressões fechadas mostrando a distribuição especial do parâmetro área planar. Notar na porção norte da área a grande concentração de depressões com área abaixo da média; essas depressões possuem altitude média superior ao restante da população.

\section{DISCUSSÕES}

A pequena variabilidade nos valores de rugosidade obtidos para a população de depressões poligonais fechadas e a semelhança destes com o índice obtido para a totalidade do carste mostram que a distribuição das irregularidades na superfície carbonática é uniforme. As depressões apresentam grande variação de área, amplitude do relevo e densidade de drenagem; a declividade é mais constante. Na região estudada, a declividade média também exprime a rugosidade do relevo, como mostra a forte correlação entre estes dois parâmetros.

$\mathrm{O}$ valor médio de circularidade expressa depressões que se desenvolvem segundo um eixo preferencial, na maioria das vezes condicionado pela direção dos planos de estratificação, que na região apresenta mergulhos médios a altos (HIRUMA et al., 1999). Outras vezes, o eixo segue a direção do gradiente hidráulico da região, em muitas situações aproximadamente perpendicular à direção das camadas. Baixos índices de circularidade também expressam depressões de forma irregular (sem um eixo preferencial bem demarcado), com rede de drenagem bem desenvolvida. Depressões mais circulares são menores e estão associadas a um menor desenvolvimento da rede de drenagem. A amplitude do relevo destas depressões é relativamente menor que a das depressões mais circulares.

As correlações obtidas entre os diversos parâmetros, integrados com conhecimentos prévios da área, permitem levantar hipóteses de evolução das depressões.

Algumas depressões poderiam ter sido formadas a partir de redes de drenagem superficiais bem desenvolvidas, que no curso de sua evolução, com o aumento da carstificação, tiveram o fluxo superficial desviado para rotas subterrâneas. Esse fenômeno também é evidenciado por KARMANN (1994), mais ao sul, na Bacia do Rio Betari. A partir da captura da drenagem, passa a existir um novo nível de base local, que, com o passar do tempo, delimita uma nova depressão fechada; parte de sua forma é herdada da bacia original.

Em outros casos, as depressões cársticas originam-se pelo abatimento do teto de condutos subterrâneos ou pela dissolução diferenciada de setores da superfície. Seja qual for a gênese, a feição inicial possui pequena área e amplitude; o contorno é aproximadamente circular. Nesta primeira etapa, formam-se pequenos canais coletores que convergem para um ponto de absorção. A drenagem começa a se organizar e o canal principal evolui segundo zonas mais favoráveis (camadas mais solúveis, planos de estratificação, fraturas e/ou gradiente hidráulico). Em função da intensidade e participação das diferentes variáveis, o desencadeamento da evolução pode ser diversificado:

- se as resistências ao desenvolvimento da drenagem são muito anisotrópicas, o desenvolvimento da depressão segue um eixo principal, dando um aspecto alongado (elíptico), caracterizado por baixos valores de circularidade. Esta situação facilita a coalescência de depressões que evoluem num mesmo eixo. Neste caso, o contorno gerado pela coalescência possui circularidade inferior ao das depressões iniciais;

- se a fonte das resistências ao desenvolvimento da drenagem é menos anisotrópica, a ero- 
são remontante dos tributários ampliará o contorno da depressão aproximadamente com a mesma intensidade em várias direções (de forma centrífuga), que, em relação à situação anterior, tenderá a criar formas com índices de circularidade mais elevados.

Cabe ressaltar que o tempo de evolução e o arranjo diversificado dos fatores envolvidos podem mesclar os cenários apresentados.

A grande concentração de pequenas depressões na porção norte da área de estudo, zona mais elevada do carste, coincide com uma região de elevada densidade de lineamentos estruturais. Nesta área o acamamento está subverticalizado e afetado por falhas de direção NNE-SSW (HIRUMA et al., 1999).

\section{CONSIDERAÇÕES FINAIS}

A utilização de técnicas de geoprocessamento para a caracterização de terrenos cársticos agilizou a obtenção de um grande número de parâmetros morfométricos que permitiram estabelecer relações entre a forma das depressões poligonais fechadas e outros atributos do relevo. Na região estudada, a comparação entre depressões mais e menos circulares mostra que as últimas possuem área planar mais desenvolvida, maior amplitude do relevo e uma maior densidade de drenagem. As irregularidades expres- sas pelo índice de rugosidade não apresentam variações significativas a despeito das formas das depressões. A rugosidade média da população de depressões fechadas não difere significativamente da obtida para a totalidade da superficie cárstica.

A baixa circularidade das depressões fechadas está associada a condicionantes estruturais, que favorecem a evolução da forma segundo um eixo preferencial; em outros casos, está associada a depressões com rede de drenagem bem desenvolvida, onde a erosão remontante dos tributários expande a depressão em diferentes direções, dando um aspecto irregular. Em algumas situações, as depressões fechadas herdaram os contornos de antigas redes de drenagem, que no curso da evolução foram desviadas para o meio subterrâneo.

O agrupamento de depressões fechadas, com áreas abaixo da média populacional no norte da área de estudo, está associado a uma zona relativamente mais elevada e de maior concentração de lineamentos estruturais.

O trabalho estabeleceu um padrão de análise, que pode ser utilizado para comparar paisagens cársticas de diferentes regiões, desenvolvidas em diferentes contextos climáticos e estruturais. O método aqui apresentado não se limita à análise do carste, podendo ser adaptado para paisagens desenvolvidas em outras litologias e diferentes escalas de trabalho.

\section{REFERÊNCIAS BIBLIOGRÁFICAS}

ALONSO, M.T.A. 1977. Geografia do Brasil Região Sudeste. IBGE - Rio de Janeiro. $677 \mathrm{p}$.

CAMPANHA, G.A.C. 1991. Tectônica proterozóica no alto e médio vale do Ribeira, Estados de São Paulo e Paraná. Tese de Doutoramento, IGc - USP, 296 p.

CHRISTOFOLETTI, A. 1980. Geomorfologia. São Paulo: Edgard Blucher, $2^{\mathrm{a}}$ edição, 188 p.

DAY, M.J. 1979. Surface roughness as a discriminator of tropical karst styles. Zeitschrift fur Geomorphologie, NF, 32: 1-8.

ELLIOT, J.K. 1989. An investigation of the change in surface roughness through time on the foreland of Austre Okstindbreen, North Norway. Computers \& Geosciences, 15 (2): 209-217.
HIRUMA, S.T.; FERRARI, J.A.; ANTONIETTI, E.; MARINHO, M.; KARMANN, I. 1999. Contribuição ao conhecimento do meio físico no Parque Estadual Turístico do Alto Ribeira - PETAR (Apiaí e Iporanga, SP) - Capítulo III: Geomorfologia. São Paulo: Instituto Geológico - SMA, 237p. (Relatório Interno).

HOBSON, R.D. 1972. Surface roughness in topography: quantitative approach. In: Spatial analysis in geomorphology. CHORLEY, R.J. (ed.), Harper and Row, p. 225-245.

HORTON, R.E. 1945. Erosional development of streams and their drainage basins: hydrophysical approach to quantitative morphology. Geol. Soc. Am. Bull.. 56(3) 275-370. 
JICA/DNPM-Jap. Intern. Coop. Ag./DNPMDepto. Nac. Prod. Min. 1983. Projeto Anta Gorda. Relatório Final.

KARMANN, I. 1994. Evolução e dinâmica atual do sistema cárstico do Alto Vale do Rio Ribeira, sudeste do Estado de São Paulo. Tese de Doutoramento, IGc-USP. $228 \mathrm{p}$.

\& SÁNCHEZ, L.E. 1979. Distribuição das rochas carbonáticas e províncias espeleológicas do Brasil. Espeleo Tema, 13:105-167.

McCONNEL, H. \& HORN, J.M. 1972. Probabilities of surface karst. In: Spatial analysis in geomorphology. CHORLEY, R. J. (ed.), Harper and Row, p. 111-113.

MILLER, V.C. 1953. A quantitative geomorphic study of drainage basins characteristic in the Clinch Mountain area. Dept. Geology, Columbia University (Technical Report, 3).

MILLER, T.E. 1982. Hydrochemistry, hydrology and morphology of the Caves Branch karst, Belize. PhD. Thesis, McMaster University.

NIMER, E. 1977. Geografia do Brasil - Região Sudeste. IBGE - Rio de Janeiro, 667 p.

PONÇANO, W.L.; CARNEIRO, C.D.R.; BISTRICHI, C.A.; ALMEIDA, F.F.M. de; PRANDINI, F.L. 1981. Mapa geomorfológico do Estado de São Paulo. São Paulo: IPT, 2v. (Monografias).

PRINGLE, J.M. 1973. Morphometric analysis of surface depressions in the Mangapu karst. MSc Thesis, University of Auckland.

TAVARES, R.\& GUTJHAR, M.R. 1999. Contribuição ao conhecimento do meio físico no Parque Estadual Turístico do Alto Ribeira - PETAR (Apiaí e Iporanga, SP) - Capítulo IV: Clima. São Paulo: Instituto Geológico - SMA, 237 p. (Relatório Interno).

WILLIAMS, P.W. 1972. Morphometric analysis of polygonal karst in New Guinea. Geol. Soc. America Bull., 83:761-796.

Endereço dos autores:

- José Antonio Ferrari e Silvio Takashi Hiruma - Instituto Geológico/SMA, Av. Miguel Stéfano, 3.900, 04301-903, São Paulo, SP - Brasil. E-mails: ferrari@igeologico.sp.gov.br, hiruma@igeologico.sp.gov.br

- Ivo Karmann - Instituto de Geociências - USP, Caixa Postal 11.348, 05422-970, São Paulo, SP - Brasil. Email: ikarmann@usp.br 